\title{
Vertical-torsional oscillations and dissociated bilateral horizontal gaze palsy in a patient with a pontine cavernous angioma
}

\author{
N Washio, Y Suzuki, T Yamaki, M Kase, K Ohtsuka
}

J Neurol Neurosurg Psychiatry 2005;76:283-285. doi: 10.1136/jnnp.2004.042663

\begin{abstract}
We report the case of a 16 year old girl with verticaltorsional oscillations. She had a 4 year history of bilateral horizontal gaze palsy caused by a cavernous angioma in the medial part of the dorsal pons. She presented with vertical oscillopsia that had worsened during the past 3 months. Unilateral three dimensional eye movements and bilateral horizontal eye movements were recorded using a magnetic search coil method and direct current electro-oculography, respectively. She had vertical-torsional oscillations (average frequency: $3.0 \mathrm{~Hz}$ ) leaving vertical saccades and pursuits intact. The average amplitudes of the vertical and torsional components were $2.0^{\circ}$ and $0.6^{\circ}$, respectively. Her horizontal rapid eye movements were severely impaired; however, her horizontal pursuits and slow phases of vestibulo-ocular reflex were only partially impaired (gain $<0.3$, oculomotor range $< \pm 9^{\circ}$ ). Convergence and divergence were intact. Lesions involving the medial part of the dorsal pons and bilateral paramedian pontine reticular formation can induce vertical and torsional oscillations without disruption of vertical rapid eye movements.
\end{abstract}

$\mathrm{S}$ ingle unit studies in cats and monkeys have shown that the pontine reticular formation contains many oculomotor related neurons. It is well known that velocity signals for horizontal rapid eye movements (saccades and fast phases of nystagmus) are generated by excitatory burst neurons $(\mathrm{EBNs})^{1}$ in the paramedian pontine reticular formation $(\mathrm{PPRF})^{23}$ and transformed into horizontal eye position signals in the so called neural integrator. ${ }^{4}$ Hence, bilateral rostral PPRF lesions in rhesus monkeys ${ }^{5}$ and humans $^{67}$ have been reported to induce selective loss of horizontal rapid eye movements without impairment of horizontal gaze holding or horizontal slow eye movements.

Omnipause neurons (OPNs) that suppress unwanted firings of EBNs for rapid eye movements in any directions were identified in the nucleus raphe interpositus (RIP) in the medial region of the caudal PPRF. ${ }^{8}$ Based on a system analysis method, Zee and Robinson proposed that an abnormal state in the activity of OPNs and/or their afferents from the superior colliculus could induce instability of the burst neurons, causing saccadic oscillations. ' However, in rhesus monkeys ${ }^{10}$ and in humans, ${ }^{11-13}$ bilateral caudal PPRF lesions including RIP induced severe disruptions of vertical and horizontal rapid eye movements but did not cause oscillations. On the other hand, lesions in the upper pontine tegmentum and/or PPRF have been reported in patients with ocular flutter ${ }^{14}$ or opsoclonus. ${ }^{15}{ }^{16}$ The site responsible for the occurrence of saccadic oscillations has been a matter of controversy. One possible neural substrate is the cell group of the paramedian tracts (PMT cell group) lying closely lateral to RIP, ${ }^{17}$ since the PMT cell groups relay eye velocity and eye position signals, which could be used as motor feedback information to stabilise the eye position, ${ }^{17}{ }^{18}$ to the cerebellar floccular region..$^{18}$

Here, we report a case of vertical-torsional oscillation and dissociated bilateral horizontal gaze palsy in a patient with lesions of the bilateral PPRF and the medial part of the dorsal pons, and discuss the lesion sites responsible for these observations.

\section{CASE REPORT}

In March 2002, a 16 year old girl presented with vertical oscillopsia that had worsened during the past 3 months. She had a 4 year history of bilateral horizontal gaze palsy due to a pontine cavernous angioma. Her corrected visual acuity was 0.8 and 0.7 for the right and left eye, respectively. Pupillary responses, intra-ocular pressure, slit lamp examinations, and funduscopic examinations were normal in both eyes. Her eye position showed orthophoria and her stereopsis was better than 60 seconds. Magnetic resonance imaging (MRI) revealed a lesion in the medial part of the dorsal pons. The lesion was $40 \mathrm{~mm}$ in diameter and showed mixed signal intensities in T1 and T2 weighted images (fig 1). The lesion was well demarcated with a peripheral rim of hypointensity reflecting haemosiderin deposition. These neuro-radiological findings were consistent with a cavernous angioma. She was referred to the neurosurgery department of our hospital in April 2002 and a partial resection of the tumour was performed 2 months later. Histological examination confirmed the pre-surgical diagnosis of a cavernous angioma. At 1 month after surgery, her oscillopsia had decreased and her corrected visual acuity of both the right and left eye had improved to 1.0.

After obtaining informed consent from the patient, we investigated her eye movements using two recording procedures sequentially. Three dimensional eye movements of the right eye were recorded using a magnetic search coil system (EPM S3020, Skalar, The Netherlands). Three dimensional eye movements were calibrated according to the methods of Hess et al $^{19}$ and analysed as rotation vector. Rotation angles in this study are shown in degrees for clarity. Bilateral horizontal eye movements were recorded using direct current electro-oculography (high cut off: $30 \mathrm{~Hz}$ ), while applying vestibular stimulation or not. The head was fixed to a vestibular chair. In addition, caloric stimulation was performed.

\footnotetext{
Abbreviations: EBNs, excitatory burst neurons; MRI, magnetic resonance imaging; OKN, optokinetic nystagmus; OPNs, omnipause neurons; PPRF, paramedian pontine reticular formation; riMLF, rostral interstitial nucleus of the medial longitudinal fasciculus; RIP, raphe interpositus; VOR, vestibulo-ocular reflex
} 

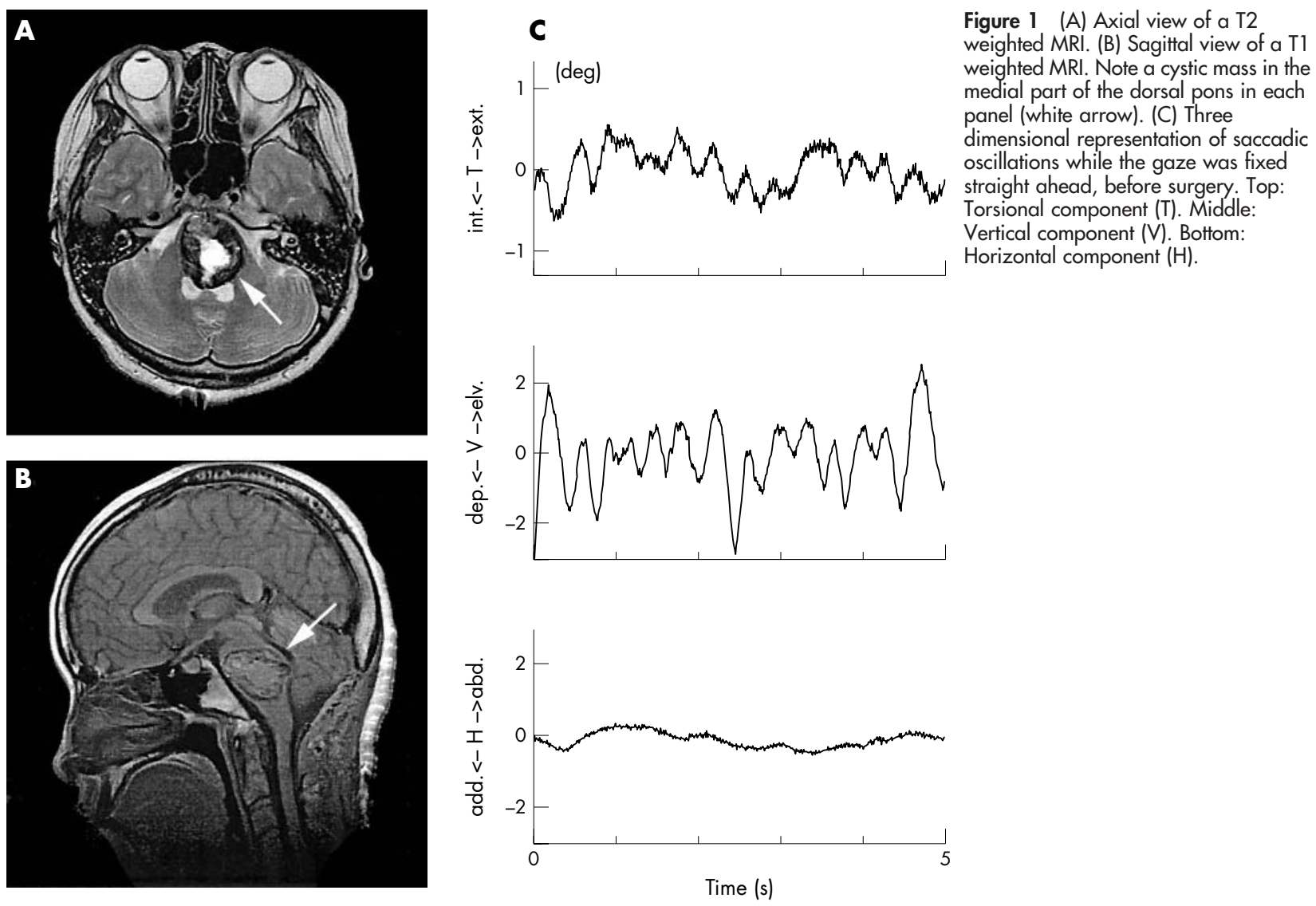

\section{Vertical and torsional eye movements}

Vertical-torsional oscillations were observed both before (fig 1C) and after surgery. Before surgery, the average amplitude and frequency of the vertical oscillations while the gaze was fixed straight ahead were $2.0^{\circ}$ (SD: $1.2^{\circ}$ ) and $3.0 \mathrm{~Hz}$, respectively. Additionally, small torsional oscillations with an average amplitude and frequency of $0.6^{\circ}$ (SD: $0.2^{\circ}$ ) and $3.0 \mathrm{~Hz}$ were observed. Although vertical oscillations were superimposed on the smooth tracking eye movements, the patient could pursue a vertically moving target in the range of $\pm 20^{\circ}$. Visually guided saccades were hypermetric with normal latencies in both upward and downward directions. Leakiness of the velocity-to-position integrator was not observed. Upward and downward optokinetic nystagmus $(\mathrm{OKN})$ was induced; however, we could not estimate its gain because vertical oscillations contaminated the slow phases of OKN. Slow saccades were not observed in the vertical direction. The amplitude-velocity relationship of upward and downward rapid eye movements was within the normal range (for example, a maximum velocity of $400 \%$ was observed in a $20^{\circ}$ saccade). The frequency of saccadic oscillations after surgery was almost identical with that before surgery, but the average amplitude of saccadic oscillations became smaller $\left(1.3^{\circ}\left(\mathrm{SD}: 0.7^{\circ}\right) / 0.5^{\circ}\left(\mathrm{SD}: 0.2^{\circ}\right)\right.$, vertical/ torsional).

\section{Horizontal eye movements}

Visually guided saccades and vestibulo-ocular reflex (VOR) fast phases were not observed either before or after surgery. Optokinetic stimulation and caloric stimulation induced only tonic deviation of the eye in the direction of slow phases. Before surgery, pursuit eye movements and VOR slow phases were preserved with maximum gains of 0.3 and 0.3 , respectively. The gain of pursuit and VOR had improved after surgery to 0.6 and 0.4 , respectively. Manually induced convergence and divergence were well preserved both before and after surgery.

\section{DISCUSSION}

In this case, a cavernous angioma in the dorsal pons induced vertical-torsional oscillations and dissociated bilateral horizontal gaze palsy. It is clear that complete impairment of horizontal rapid eye movements was due to bilateral PPRF lesions, similar to the results for experimental lesions in monkey. ${ }^{5}$ Additionally, it seems that the PMT cell group, OPNs in RIP, and their efferents and afferents were extensively impaired because the cavernous angioma was in the midline dorsal pons (fig $1 \mathrm{~A}$ and $\mathrm{B}$ ). When OPNs in RIP were neurotoxically lesioned with ibotenic acid in rhesus monkeys, the peak velocity of horizontal saccades decreased dramatically and that of vertical saccades decreased moderately. ${ }^{20}$ Although moderate reduction of the peak velocity of vertical saccades could have occurred in our case, the absence of slow saccades indicated that the vertical-torsional pulse generator in the rostral interstitial nucleus of the medial longitudinal fasciculus (riMLF) was intact. Pharmacological inactivation of the PMT cell group in cat induced a vertical leaky integrator combined with vestibular imbalance. ${ }^{21}$ In our case, the vertical saccade was hypermetric without a postsaccadic drift, indicating pulse-step mismatch but not a leaky integrator. We believe that the leakiness of the vertical integrator and vestibular imbalance might have been compensated for by prolongation of the time constant during the long period of impairment of the PMT cell group.

The vertical-torsional oscillations in this case report were similar to opsoclonus and classified as saccadic intrusions without a saccadic interval. ${ }^{22}$ Although the mechanism underlying the vertical-torsional oscillations is uncertain, 
lesions in the upper pontine tegmentum and/or PPRF have been reported in patients with saccadic oscillations. ${ }^{9}{ }^{14-16}$ Vertical oscillations have also been reported in locked-in or comatose patients, due to severe pontine strokes. ${ }^{23-25}$ The average frequency and amplitude of the vertical oscillations in our case were in the range of the frequencies observed in these studies $(2-5 \mathrm{~Hz})$ and slightly smaller than the observed amplitudes $\left(3-45^{\circ}\right)$, respectively. As we described in the introduction, Zee and Robinson have hypothesised that saccadic oscillations such as ocular flutter and opsoclonus could be induced by lesions of OPNs in RIP, or by their afferents from the superior colliculus'; however, selective chemical micro-lesions of RIP did not induce oscillatory eye movements in rhesus monkeys. ${ }^{20}$ These reports suggest that an isolated RIP lesion is not sufficient to induce vertical-torsional oscillations. Because the PMT cell group relays efference copy signals to the cerebellar floccular region, and this is important in maintenance of fixation, ${ }^{17} 1822$ we speculate that combined lesions of RIP and the PMT cell group are probably necessary to induce saccadic oscillations.

\section{Authors' affiliations}

N Washio, Y Suzuki, K Ohtsuka, Department of Ophthalmology, Sapporo Medical University, School of Medicine, Sapporo, Japan T Yamaki, Department of Neurosurgery, Sapporo Medical University, School of Medicine, Sapporo, Japan

M Kase, Department of Ophthalmology, Teine Keijinkai Hospital, Sapporo, Japan

Competing interests: none declared

Correspondence to: Yasuo Suzuki, Department of Ophthalmology, Sapporo Medical University, School of Medicine, S1 W16 Chuou-ku Sapporo, 060-8543, Japan; yasuzuki@sapmed.ac.jp

Received 7 April 2004

In revised form 10 June 2004

Accepted 15 June 2004

\section{REFERENCES}

1 Grantyn R, Baker R, Grantyn A. Morphological and physiological identification of excitatory pontine reticular neurons projecting to the cat abducens nucleus and spinal cord. Brain Res 1980;198:221-8.

2 Bender MB, Shanzer S. Oculomotor pathways defined by electric stimulation and lesions in the brain stem of the monkey. In: Bender MB, eds. The oculomotor system. New York: Harper \& Row, 1964:81-140.
3 Goebel H, Komatsuzaki A, Bender MB, et al. Lesions of the pontine tegmentum and conjugate gaze paralysis. Arch Neurol 1971;24:431-40.

4 Fukushima K, Kaneko CRS, Fuchs AF. The neuronal substrate of integration in the oculomotor system. Prog Neurobiol 1992;39:609-39.

5 Henn V, Lang W, Hepp K, et al. Experimental gaze palsies in monkeys and their relation to human pathology. Brain 1984;107:619-36.

6 Pierrot-Deseilligny C, Goasguen J, Chain F, et al. Pontine metastasis with dissociated bilateral horizontal gaze paralysis. I Neurol Neurosurg Psychiatry 1984;47(2): 159-64.

7 Kommerell G, Henn V, Bach $M$, et al. Unilateral lesion of the paramedian pontine reticular formation. Loss of rapid eye movements with preservation of vestibule-ocular reflex and pursuit. Neuro-ophthalmology 1987;7:93-8.

8 Büttner-Ennever JA, Cohen B, Pause M, et al. Raphe nucleus of pons containing omnipause neurons of the oculomotor system in the monkey, and its homologue in man. J Comp Neurol 1988;267:307-21.

9 Zee D, Robinson DA. A hypothetical explanation of saccadic oscillations. Ann Neurol 1979;5:405-14.

10 Hepp K, Henn V, Vilis T, et al. Brainstem regions related to saccade generation. In: Wurtz RH, Goldberg ME, eds. The neurobiology of saccadic eye movements. Amsterdam: Elsevier, 1989:105-212.

11 Hanson MR, Hamid MA, Tomsak RL, et al. Selective saccadic palsy caused by pontine lesions: clinical, physiological, and pathological correlations. Ann Neurol 1986;20:209-17.

12 Slavin ML. A clinicoradiographic correlation of bilateral horizontal gaze palsy and slowed vertical saccades with midline dorsal pontine lesion on magnetic resonance imaging. Am J Ophthalmol 1986;101:118-20.

13 Toyoda K, Hasegawa Y, Yonehara T, et al. Bilateral medial medullary infarction with oculomotor disorders. Stroke 1992;23:1657-9.

14 Schon F, Hodgson TL, Mort D, et al. Ocular flutter associated with a localized lesion in the paramedian pontine reticular formation. Ann Neurol 2001;50:413-6.

15 Hattori T, Hirayama K, Imai T, et al. Pontine lesion in opsoclonusmyoclonus syndrome shown by MRI. J Neurol Neurosurg Psychiatry 1988;51:1572-5.

16 Hormigo H, Dalmau J, Rosenblum MK, et al. Immunological and pathological study of anti-Ri-associated encephalopathy. Ann Neurol 1994;36:896-902.

17 Büttner-Ennever JA, Horn AK, Schmidtke K. Cell groups of the medial longitudinal fasciculus and paramedian tracts. Rev Neurol (Paris) 1989; 145:533-9.

18 Büttner-Ennever JA, Horn AK. Pathways from cell groups of the paramedian tracts to the floccular region. Ann N Y Acad Sci 1996;781:532-40.

19 Hess BJM, van Opstal AJ, Straumann D, et al. Calibration of threedimensional eye position using search coil signals in the rhesus monkey. Vision Res 1992;32:1647-54.

20 Kaneko CRS. Effect of ibotenic acid lesions of the omnipause neurons on saccadic eye movements in rhesus macaques. J Neourophysiol 1996;75:2229-42

21 Nakamagoe K, Iwamoto Y, Yoshida K. Evidence for brainstem structures participating in oculomotor integration. Science 2000;288:857-9.

22 Leigh RJ, Zee DS. The neurology of eye movements, 3rd ed. New York: Oxford University Press, 1999.

23 Lawrence WH, Lightfoote WE. Continuous vertical pendular eye movements after brain-stem hemorrhage. Neurology 1975;25:896-8.

24 Stacy CB. Continuous vertical ocular flutter, asynchronous palatal myoclonus, and alpha coma. Neuro-ophthalmology 1982;2:147-56.

25 Keane JR. Acute vertical ocular myoclonus. Neurology 1986;36:86-9. 